\title{
Determinants of Rice Farmers' Risk-attitudes in Rural Ghana: An Operational Domain Scale Approach
}

\author{
Kwame Asiam Addey \\ Research Assistant, Dept. of Agribusiness \& Applied Economics \\ North Dakota State University. Email: Kwame.addey@ndsu.edu
}

Received: December 18, 2017

Accepted: January 1, 2018

doi:10.5296/jas.v6i1.12314

URL: https://doi.org/10.5296/jas.v6i1.12314

Funding Agencies: Philip Foster (Aqua Africa Ltd) and Department of Agribusiness and Applied Economics, North Dakota State University.

\begin{abstract}
Production of rice in Ghana has been marred by various production risks which reduce the yield potentials of farmers. The introduction of agricultural insurance presents an opportunity to mitigate these risks. However, individual preferences for risk-mitigating strategies are dependent on their risk attitudes. And this is affected by a broad spectrum of characteristics. This study, therefore analysed the determinants of the risk attitudes of rice farmers in the Greater Accra region of Ghana. Their risk-attitudes were obtained using an operational domain-scaled statement set. Majority of the respondents $(96.14 \%)$ were found to be risk averse. The gender, household size, land tenure system and the ratio of non-farm income to rice farm income were found to significantly affect the probability of risk neutrality whiles marital status, land tenure system and the probability of failure to achieve target yields were observed to significantly influence the probability of being risk-loving. Further study is recommended to identify the relationship between these risk attitudes and adoption of crop insurance.
\end{abstract}

Keywords: Cronbach-alpha; Risk-attitude; Multinomial logit; Operational Domain Scale

JEL Classification Codes : D01; D03 


\section{Introduction}

Amanor-Boadu (2012) highlighted on the terrifying facts that per capita consumption of rice in Ghana has increased from $17.5 \mathrm{~kg}$ per annum between 1999 and 2001 through $22.6 \mathrm{~kg}$ per annum between 2002 and 2004 to $38 \mathrm{~kg}$ per annum by the year 2011 and was projected to reach $63 \mathrm{~kg}$ per annum by 2015. This increase has transformed rice into Ghana's most important cereal food crop after maize. The demand for rice was expected to soar up to a consumption of $63 \mathrm{~kg}$ per capita. However, the country imports about two-thirds of rice amounting to about 350 million US dollars of the government's budget. This signifies the need to improve upon domestic production of rice to reduce the import bill on rice.

Domestic production of rice is nonetheless marred by various production risks which reduce the production potential of rice farmers in Ghana. Kranjac-Berisavljevic et al. (2003) indicated that many rice farmers are exposed to risks ranging from drought, flooding to pests and diseases. Their knowledge of risks associated with the production prevents rice farmers from making greater investments in their rice production in terms of acreage of production. Yet, the situation is not bleak with the advent of agricultural insurance in recent times through the effort of the Ghana Agricultural Insurance Pool with the aid of GIZ and the German government. Akyoo et al. (2013) confirmed that one notable advantage of crop insurance schemes is the guarantee of protection against frequent crop failures due to occurrence of natural hazards like floods windstorms, droughts, landslides, eruptions, etc. and this has subsequently enabled farmers to access credit, venture in new farming technologies and thus made way for greater investments in agriculture.

The formulation of agricultural insurance schemes will be practically immaterial without a comprehension of the risk attitudes of the target consumers. The theory of risk has remained pervasive in different sectors of life. It is considered as a pivotal section of interest in decision-making with practical examples being in the areas of finance, health, sports, agriculture, education just to mention a few. Individuals' decision making is governed primarily by their risk-attitudes which is most often attributed to external factors such as past personal experiences, observed experiences, extent of exposure or enlightenment in that field of decision making, among others. Sadati et al. (2010) concurred that risk plays an important role in human livelihood particularly in third world countries where farmers are exposed to weather vagaries and price shocks and further elaborated that understanding of risk and risk attitudes is important for policy makers. Adegeye and Dittoh (1985) revealed that a considerable majority of agricultural decisions are taken under risks and uncertainties.

The impact of risks on farmers and other agricultural related workers cannot be over-stated when it comes to their decision-making processes. Agriculture is considered by many as a very risky enterprise. Hurley (2010) supports this notion and further stated unambiguously that agricultural production worldwide is inherently risky. This puts poor farmers at a risk of failing to meet subsistent needs. Adverse climate change concerns have led to a worsened perception of the riskiness of agriculture. This has led to irregular rainfall patterns especially in sub-Saharan where most of the farmers are unfortunately dependent on rainfall. The adverse climate changes have also led to increases in average temperature in these areas 
which are not favourable for plant growth and crop cultivation. Apart from the risks mentioned previously, natural disasters such as flooding, wind, pests and diseases also play huge impacts in escalating the risky nature of agriculture.

Agricultural risks ultimately lead to loss in crop yields if not properly understood and managed. This trend subsequently leads to a recurring cycle of poverty amongst farmers. Binswanger who is mostly regarded as the father of risk identified as far back as 1980 that majority of farmers are risk averse using an incentive-based experimental gambling approach. There is the imminent need to understand the risk attitudes of rice farmers and the factors which affect these risk behaviours.

With regards to the current situation of the rice sector and fortunate emergence of agricultural insurance in Ghana, the general objective of this paper is to analyse the factors affecting the risk attitudes of rice farmers. The specific objectives are to: determine the frequency and severity of risks faced by the farmers over a five-year period of farming, assess their risk attitudes and finally to identify the factors affecting the risk attitude of farmers.

\section{Review of Literature}

\subsection{Risk}

Risk is generally defined as the probability of occurrence of a negative outcome or event. These negative outcomes may include injuries, damage, loss of wealth, deterioration of health, loss of field crops just to mention a few. The definition of risk in some literature is interchanged with uncertainty while some distinguish clearly between these two concepts. Classification of risks in agriculture is highly varied. It has mostly been dependent on the standpoint of the risk expert reviewing it or the sector of agriculture (i.e. crop or animal sector) doing the analysis in question. Mare (2014) agreed to this assertion by indicating that there is no agreed classification of risk and it may thus be classified according to the purpose of its use.

Mare (2014) further indicated that Newbery and Stiglitz (1981) first distinguished between systematic and non-systematic risk characteristics where systematic risk is defined as events that repeat in a pattern of probabilities over time in such a way that the actuarial odds can be analysed and estimated over time whiles non-systematic risk is just the opposite by the fact that it is recognised by imperfect records of occurrence and no pattern can be identified in the distribution of outcomes.

Nto et al. (2014) also came up with a compilation of the risks of agriculture production and these are given as follows; political risk, technical risk, social risk, financial risk and market risks. Political risks involve those from politically motivated decisions. Such decisions may at times present itself as a negative shock to farmers who are almost always not prepared. Example of political risks are removal of input subsidies to cut government expenditure, reduction of import taxes of competing food produce like rice, etc. Other political factors that serve as a risk to farmers are high tariffs on electricity, inadequate storage facilities and bad roads (i.e. with the use of public goods and regulations). Technical risks are a group of events that arise from production in agriculture and directly affect the output of the farmers. Farmers 
and to some large extent related policy makers in most cases have little or no control over these events. Examples of technical risks are pest, diseases infestation, weather related events like drought, heavy rainfall leading to flooding, excessive temperature and hail. Social risks arise most largely from the results of farmers' interaction with the society or the community in which their farming activities occur. Some of these are boundary disagreements, land tenure disputes and theft.

The success of every project has a high relative dependency on the funding available to undertake it. Farming cannot be an exemption to this rule. Undertaking a project without adequate resources can be extremely frustrating. Financial risks in farming occurs when farmers do not get adequate monetary resources to carry out all the essential activities required for a successful farming season. In some events farmers are refused loans by financial institutions whiles in cases when their loans are approved, they are not disbursed on time and only reach the farmers way into the production season when its need might have passed. In other circumstances, too, farmers might not also have adequate knowledge of the required amount they need for production, thereby requesting for insufficient funds.

The transaction point of agriculture's value chain is not devoid of risks. This occurs in conditions when farmers are not able to obtain the targeted price for their farm produce. This may be a consequence of situations where there is excess supply of food over its demand. In worse scenarios, farmers do not even get buyers for their produce. This situation culminates to market risks. (Nto, 2014)

Similarly, Ellis (1998) indicated that there are four types of risks: natural hazards, market fluctuations, social uncertainty and political instability. Irrespective of the variations in classifications of risks and uncertainties under agriculture, they all possess components of the risk categorization done by Nto et al. (2014).

\subsection{Risky Behaviour and its Impacts on Agricultural Decision Making}

Harwood et al. (1999) stated that because farmers vary in their attitude toward risk and their ability to address risky situations, risk management cannot be viewed within a "one size fits all" approach. This is in the sense that one risk management approach cannot be used as a solution for all the problems or risks that can be potentially encountered.

Furthermore, a farmer's decision under risk and uncertainty involves a combination of many activities which are bound to yield uncertain outcomes and different levels of expected returns which are in most cases with low probabilities of prediction. Farmers therefore make their decisions based on their risk-nature. Hao (2010) elaborated on the fact that there are great differences among the three types of risk-behaviour categories in farmer's supply response. Nmadu et al. (2012), indicated that farmers' risk attitudes are major determinants of the rate of diffusion of new technologies among them and the outcome of rural development programs. They further noted with reference from (Adebusuyi, 2004; Alderman, 2008) that risks cause farmers to be less willing to undertake activities and investments that have higher expected outcomes but carry with them high risk of failure 


\subsection{Methods of Risk Elicitation}

Farsi (2007) indicated that ignoring consumers' risk-aversion toward new non-market goods could lead to an underestimation of the marginal willingness to pay. There has been a considerable intensity of research into the methods of determining the risk attitude of individuals even though Deck and Reyes (2010) created the awareness that there is little consistency among risk elicitation techniques. Leuermann (2012) indicates that since the first formalization by Bernoulli (1738), many theoretical models incorporate assumptions about the subjects' risk preferences which have a significant impact on the outcome of the models.

This has been with regards to the fact that individuals are faced with uncountable risk decisions in their everyday lives. From a risk decision as simple as deciding to iron one's shirt for work before the next day to avoid the effect of a power outage to a complex risk decision such as deciding to invest a huge sum of money into a business venture such as tilapia farming, the prevalence of risk decisions cannot be over-elaborated in our everyday lives. Bard and Barry (2001) stated that the Expected utility theory (EUT) has been the most widely used theoretical framework for eliciting farmers' risk attitudes. Even though the list of risk eliciting methods is non-exhaustive, a few would be discussed.

The first method of risk elicitation that comes to mind in the discussion of risk elicitation is the Holt and Laury (2002) multi-price list method of risk aversion measure. Maier and Maximilian (2010) explicitly indicated that to measure individual's risk attitudes, the multiple price-list method of Holt and Laury (2002) has become the standard way used in experiments. As indicated by Reynaud and Couture (2010), the type of risk elicitation method used to measure risk aversion may have an influence on the results obtained. It is therefore imperative that the methods of risk elicitation with their attached advantages and shortfalls are highlighted. Their work took into consideration four main methods i.e. Eckel and Grossman, Holt and Laury (lottery tests), risk-taking Psychometric questionnaire and self-report of perceived risk attitudes for different domains.

Reynaud and Couture (2010) in their study in which the respondents were French farmers obtained the following results: first, farmers appear to be more risk averse using the Eckel and Grossman lottery than using the Holt and Laury one. However, attitudes towards risk were significantly correlated across lotteries which means that the ranking of risk preferences seems to be preserved. Second, risk preferences appear to be context-dependent. French farmers are highly risk averse for decisions belonging to financial and ethical domains. They further explained that the farmers report a higher willingness to take risk for professional decisions. Lastly, using the psychological questionnaire, it was discovered that the risk attitude elicited through lottery choices often correlates with risk attitude toward investments.

In their research titled "A theoretical and experimental appraisal of five risk elicitation methods", Crosetto and Filippin (2013) concluded that the best task for risk elicitation is one that is most in line with the experimenter's aims. What is important is to be aware of the different dimensions along which the tasks differ. For instance, the Eckel and Grossman and the investment game had better be used to control for risk attitudes in situations where losses are salient, while the Bomb Risk Elicitation Task provides a pure measure of risk aversion. 
Budgetary reasons could lead the researcher to opt for a simple questionnaire, although the correlation with incentivised tasks is low. They further advised that the simplest tasks should be preferred particularly when working in low-numeracy context, and single-choice tasks should be preferred to multiple-choice tasks for many reasons. The choice of the right task always involves trade-offs, however, and it is up to the researcher to resolve them in the best way. In their work they compared the following elicitation methods: Multiple Price list (Holt and Laury), ordered lottery selection (Eckel and Grossman), The Investment Game of Charness, Gneezy and Potters (CGP), the Balloon Analogue Risk Task (Balloon), the Bomb Risk Elicitation Task (BRET) and Questionnaire methods (DOSPERT and SOEP).

\section{Methodology and Method of Analysis}

\subsection{Study Area}

Data for the study was collected from 265 rice farmers in the Ga Dangme west district of the Greater Accra region of Ghana. A set of semi-structured questionnaires were administered to the respondents in a one-on-one verbal interview. The respondents were randomly selected based on a simple random sampling technique. Questions about respondents farming activities, previous risks encountered, their severities and socioeconomic characteristics were sought. After the data cleaning process, 259 of the questionnaires were found to be valid for this analysis. The major crops in the study area are rice, mango, pawpaw, plantain and maize. The area has the highest average yield for rice of about 5.4 tonnes per hectare which is consistently higher than the national average of 2.7 tonnes per hectare. The major rice cultivation areas in the study area are Akuse and Asutuare. The Ga Dangme West is geographically located in the South-Eastern part of Ghana, and it lies between latitude $5^{\circ} 45^{\prime}$ south and $6^{\circ} 05^{\prime \prime}$ North and Longitude $0^{\circ} 05^{\prime}$ East and $0^{\circ} 20^{\prime}$ West. The District is part of sixteen (16) Districts in the Greater Accra Region and has its capital as Dodowa. The District shares boundaries with Yilo Krobo District, Manya Krobo District and Asuogyaman to the North. It is also bounded in the east by Ada West whiles it is bounded to the west by Akwapim North Municipal and Tema metropolitan.

\subsection{Determination of risk frequency and severity of occurrence}

Identification of the frequencies and severity of risks encountered by the farmers over the past 5 years was aided with the use of descriptive statistics. A set of risks that had been identified and selected from literature and upon discussions with farmers and extension agents in a pretext were presented to the farmers for them to indicate how many times they had encountered each of the risks in the past five years (ten seasons: both major and minor seasons) and their perceived highest percentage severity of damage.

The frequencies of occurrence for each individual risk were summed up among the farmers. The summations were then divided by the total number of valid questionnaires (259) to obtain the frequency of each risk. The probability of the risk's occurrence was then gained by dividing through the average frequencies by 10 which represents the number of seasons of cultivation.

The farmers were made to indicate their perceived highest percentage of damage related to 
the occurrence of each risk on their farms. These were also summed up and divided by the number of farmers who had encountered each risk to get the average severity.

\subsection{Identification of Risk Status}

A risk attitudinal scale with a set of questions relevant to farmers' farm-related decisions was used to identify the risk status of the farmers. This method of measuring the risk aversion of the farmers was adapted from Nmadu et al. (2012) who presented a set of ten questions to the farmers which were related to their risk seeking behaviour. Following from that and applying to this study, each farmer was made to choose his response to the questions from five (5) indicating strongly disagree to one (1) indicating strongly agree. The reliability of the risk attitudinal statements was tested using the Cronbach's alpha coefficient of reliability. The mean response of each farmer was determined and used to classify their risk attitudes as follows; 1.00 - 2.49 Risk Averse, 2.5 Risk Neutral and 2.51 -5.00 Risk-seeking.

\subsection{Specification of the Multinomial Logistic Regression Model}

The factors affecting the farmers' risk attitudes were identified using the multinomial logit regression model. It is recommended when there are choices amongst a set of dependant variables which has more than two options. The risk attitude is represented as the dependent variable which takes three forms, 0 for Risk Averse, 1 for Risk Neutral and 2 for Risk Loving. This method is followed from Nmadu et al (2012); the probability that an ith farmer would belong to any of these three levels (the $j$ th group) can be expressed mathematically as;

$$
P_{i j}=\frac{e^{\beta_{j} X_{i}}}{1+\sum_{k=j}^{j} e^{\beta_{k} X_{i}}}
$$

This can then be generalised as

$$
P_{i j}=\frac{e^{\beta_{j} X_{i}}}{1+\sum_{k=0}^{j} e^{\beta_{k} X_{i}}}
$$

The probability of being in the base outcome group or group 1 is given as

$$
P_{i 1}=\frac{e^{\beta_{j} X_{i}}}{1+\sum_{k=1}^{s} e^{\beta_{k} X_{i}}}
$$

Where $\mathrm{i}=1,2 \ldots . . \mathrm{n}$ independent variables;

$\mathrm{k}=0,1,2$ (three groups);

$\beta j=a$ vector of parameters that relates Xi's to the probability of being in group $j$ where $j=3$ groups. The independent variables included in the model are presented in table 1.0 
Table 1.0: Description and measurement of independent variables

\begin{tabular}{|c|c|c|}
\hline Variable & Description & Measurement \\
\hline Age & Age of the respondent farmer & Years \\
\hline Sex & Sex of respondent & 1 if male, 0 if otherwise. \\
\hline Marital & Marital Status of respondent & 1 if married, 0 if otherwise \\
\hline Edu & Highest educational level attained & $\begin{array}{l}1 \text { if never been to school, } 0 \text { if otherwise } \\
1 \text { if primary school, } 0 \text { if otherwise } \\
1 \text { if JHS school, } 0 \text { if otherwise } \\
1 \text { if SHS school, } 0 \text { if otherwise } \\
1 \text { if Tertiary school (polytechnic/ } \\
\text { diploma) attained, } 0 \text { if otherwise } \\
1 \text { if Tertiary school (degree) attained, } 0 \text { if } \\
\text { otherwise }\end{array}$ \\
\hline $\begin{array}{l}\text { Household } \\
\text { size }\end{array}$ & $\begin{array}{l}\text { Number of people rice farmer } \\
\text { stays with on the same compound } \\
\text { with }\end{array}$ & Absolute number \\
\hline Riceexp & Years of rice farming experience & Years \\
\hline Yield & $\begin{array}{l}\text { Quantity of output receive per } \\
\text { hectare }\end{array}$ & Tons/hectare \\
\hline Landten & Method of land acquisition & $\begin{array}{l}1 \text { if owner i.e. no rent paid, } 0 \text { if } \\
\text { otherwise }\end{array}$ \\
\hline Ofartio & $\begin{array}{l}\text { Ratio of farmer non-rice farm area } \\
\text { to rice farm area }\end{array}$ & fraction \\
\hline Offincratio & $\begin{array}{l}\text { Ratio of non-farm income to farm } \\
\text { income }\end{array}$ & Fraction \\
\hline Extmeet & $\begin{array}{l}\text { Number of meetings with } \\
\text { extension agents within a year }\end{array}$ & Absolute number \\
\hline Failprob & $\begin{array}{l}\text { Probability that a farmer will not } \\
\text { meet his/her expected yield of } \\
\text { about } 5.4 \text { tonnes per hectare }\end{array}$ & Fraction \\
\hline
\end{tabular}

\section{Results and Discussions}

\subsection{Descriptive Statistics of respondents}

The survey showed that the average age among the farmers was 43.4 years with a range of 48 peaking at 70 . There was evidence of male dominance in rice farming as $80.31 \%$ were revealed by the study to be males. The survey respondents were further skewed towards being married, as $69.59 \%$ of them were found to be married. A full description ${ }^{1}$ of these and other socioeconomic characteristics of the survey respondents can be found in table 2.0 and 3.0 for quantitative and qualitative variables respectively.

\footnotetext{
1 Tables 2 to 7 were calculated from 2015 survey data from the Greater Accra region of Ghana
} 


\subsection{Identification of Risks faced by farmers in five years}

It was observed that wind was the most frequent risk among the farmers with a frequency of occurrence of 4.09 times per farmer over a period of 5 years or 10 seasons (i.e. major and minor season of each year). This was followed by pests and diseases with a frequency of 3.84 times per farmer. The least occurring risk was untimely distribution of credit of a frequency of 0.06 times per farmer for 5 years. The risk with the highest severity as perceived by the farmers was again found to be wind with an average severity of $44.62 \%$ whiles the one with the least perceived severity was unfavourable schedule of payment. A summary of the frequency and severity of risks are explicitly presented in table 4.0.

Table 2.0: Quantitative Variables

\begin{tabular}{lrrr}
\hline Variable & Minimum & Maximum & Mean \\
\hline Age (years) & 22 & 70 & 43.34 \\
Seasonal Rice Income(GHS) & 1500 & 12000 & 5371.74 \\
Household Size (Number) & 1 & 30 & 6.20 \\
Seasonal Yield (tons/ha) & 2.475 & 8.28 & 5.22 \\
Farm size (hectare) & 0.4 & 20 & 2.50 \\
\hline
\end{tabular}

Table 3.0: Qualitative Variables

\begin{tabular}{llrr}
\hline Variable & & Frequency & Percentage (\%) \\
\hline Education & No Education & 16 & 6.18 \\
& Primary Education & 37 & 14.29 \\
& JHS/Middle School & 82 & 31.66 \\
& SHS/SSS & 109 & 42.08 \\
& Tertiary(1) & 11 & 4.25 \\
Sex & Tertiary (2) & 4 & 1.54 \\
Marital Status & Male & 208 & 80.31 \\
& Female & 51 & 19.69 \\
Land Tenure & Married & 180 & 69.59 \\
& Single & 79 & 30.50 \\
Risk Status & Owner & 11 & 4.25 \\
& Otherwise & 248 & 95.75 \\
& Risk Averse & 249 & 96.14 \\
& RiskNeutral & 5 & 1.93 \\
& Risk Loving & 5 & 1.93 \\
\hline
\end{tabular}

\subsection{Assessment of Farmers' Risk Attitude}

The reliability of the 10 statements was tested using the Cronbach's alpha coefficient. Table 5.0 shows the ten statements used. These were revealed as having an alpha value of 0.364 which is below the optimally required alpha value. Nunnally et al., (1978) indicated that the optimum alpha value according to the rule of the thumb is 0.7 . If any value below this is 
obtained for a set of statements, the scale can be optimised by deleting weakly correlated statements until a higher Cronbach alpha's coefficient was obtained. After following this procedure, the higher alpha value of 0.531 was attained with only 4 statements remaining. The results of these statements are shown in table 6.0. The four statements were as such used in determining the risk attitudes of the farmers. It was realised that 249 of the farmers are risk averse and 5 each being Risk Neutral and Risk Loving.

Table 4.0: Frequency and severity of Risks encountered by the farmers

\begin{tabular}{lrrrr}
\hline Risk Number & Freq. & Probability & $\begin{array}{r}\text { Highest } \\
\text { Severity } \\
(\%)\end{array}$ & $\begin{array}{r}\text { Average } \\
\text { Severity } \\
(\%)\end{array}$ \\
\hline Pests and Diseases & & & 100 & 29.32 \\
Drought & 3.84 & 0.384 & 80 & 28.52 \\
Flood & 1.96 & 0.196 & 100 & 28.32 \\
Lack of improved variety & 1.45 & 0.145 & 50 & 22 \\
Low level of technology & 0.10 & 0.010 & 50 & 21.83 \\
Wind & 1.53 & 0.153 & 100 & 44.62 \\
High input prices & 4.09 & 0.409 & 50 & 20.11 \\
Theft & 1.95 & 0.195 & 25 & 10.11 \\
High Interest Rates & 0.18 & 0.018 & 40 & 19.29 \\
Untimely distribution of credit & 0.41 & 0.041 & 40 & 25 \\
Unfavourable schedule of & 0.06 & 0.006 & 15 & 10 \\
payment & 0.09 & 0.009 & & \\
\hline
\end{tabular}

Table 5.0: Results of Reliability test for 10 Statements

\begin{tabular}{lrr}
\hline Statement & $\begin{array}{r}\text { Corrected } \\
\text { Item-Total } \\
\text { Correlation }\end{array}$ & $\begin{array}{r}\text { Cronbach's } \\
\text { Alpha if } \\
\text { Item } \\
\text { Deleted }\end{array}$ \\
\hline $\begin{array}{l}\text { 1. My enterprise is diversified } \\
\text { 2. My farm is guarded by human scarecrows against birds }\end{array}$ & 0.085 & 0.359 \\
3. I complement my farm income with non-farm income & 0.035 & 0.370 \\
4. I have some of my assets in liquid(cash) form & 0.305 & 0.385 \\
5. By my experience i engage in only less risky enterprise & 0.024 & 0.240 \\
6. I secure credit to expand my farm enterprise & -0.009 & 0.415 \\
7. I have tested the source of irrigation water for my farm & 0.109 & 0.414 \\
8. I plant resistant crop varieties in my farm & 0.283 & 0.353 \\
9. I obtain market information before sale of my farm & 0.340 & 0.271 \\
produce & & \\
10.My farm activities are flexible enough to accommodate & 0.385 & 0.263 \\
changes when they are necessary & & \\
\hline
\end{tabular}


Table 6.0: Statements with high reliability

\begin{tabular}{lrr} 
Statement & $\begin{array}{r}\text { Corrected } \\
\text { Item-Total } \\
\text { Correlation }\end{array}$ & $\begin{array}{r}\text { Cronbach's } \\
\text { Alpha if Item } \\
\text { Deleted }\end{array}$ \\
$\begin{array}{l}\text { 1. My enterprise is diversified } \\
\text { 2. I plant resistant crop varieties in my farm }\end{array}$ & 0.182 & 0.594 \\
$\begin{array}{l}\text { 3. I obtain market information before sales of my } \\
\text { farm produce }\end{array}$ & 0.353 & 0.433 \\
$\begin{array}{l}\text { 4. My farm activities are flexible enough to } \\
\text { accommodate changes when they are necessary }\end{array}$ & 0.411 & 0.418 \\
\hline
\end{tabular}

\subsection{Factors affecting the Risk Behaviour of Farmers}

The factors affecting the risk status of farmers using the multinomial logit regression is presented in table 7.0. From the table, the overall likelihood ratio $\left(X^{2}\right)$ is statistically significant at $1 \%$ which means that the independent variables used in the model are significant determinants of the risk attitudes of the farmers. This a harbinger of adequate explanation of the dependent variable by the independent variables included in the model. This is confirmed by the considerably high $\mathrm{R}^{2}$ of $41.06 \%$. Observably, there is variance of significance of the independent variables among the groups of risk attitudes. Sex of respondents, household size of the farmers, type of land tenure system being practiced by the respondents and the ratio of the respondents' non-farm income to rice farm income were found to have an influence on the respondent's risk neutrality. The marital status of farmers, land tenure system of farmers, the ratio of the respondents' non-rice farm area to rice farm area and probability of failure to achieve the target yield of 5.4 tons per hectare were found to have a significant influence on the probability of being risk loving.

From table 7.0, the likelihood of risk neutrality is increased when the farmer is a male. This is understandable because majority of males in Ghana based on the traditional setup are burdened with a lot of responsibilities, this therefore reduce their probability of being risk seeking but increase their extent of risk aversion to being risk neutral. This result is consistent with the results of Dohmen et al. (n.d.) who indicated that women are more likely to be risk averse than men. It was also found from the regression that an increase in household size increased the probability of an individual being risk neutral. This confirms the notion that an increase in household size will mean increased responsibility. Hence farmers would not want to be risk averse and lose opportunities of gaining income yet still they wouldn't want to be over-ambitiously risk seeking to lose all they have and as such are risk neutral.

The results also indicate that the probability of being risk neutral is increased if the farmer owns the land on which he is cultivating. In practice, a farmer who owns the land on which he farms is normally not motivated to seek risks because there wouldn't be any pressure on $\mathrm{him} / \mathrm{her}$ to raise money to pay any land rental. An increase in the ratio of non-rice farm income to rice farm income increases the probability of being risk averse and this is intuitively meaningful because a farmer who is committed to obtaining higher income outside 
his/her rice farming shows how unwilling he/she is to take the risk of relying vastly on rice cultivation alone. It was also deduced from the regression results that married farmers are more likely to be risk loving than their non-married counterparts. This may arise from the intuition that married farmers are motivated to take risks with the knowledge that they would get support from their spouses in case of any losses occurring in taking such risks.

Even though farmers who own their farmlands are more likely to be risk neutral, they tend to be also less risk loving than their counterparts who do not who their farmlands. This behaviour can be significantly imposed from the fact that farmers who do not own their farmlands may want to take major risks in other to obtain certain amount of returns to make up for land rentals and other costs. The multinomial logistic regression again showed that respondents with a higher ratio of non-rice farm area to rice farm area were less likely to be risk loving than their counterparts who had a lower ratio. This reveals that those with higher ratios did not seem interested in pursuing further risks. Lastly the probability of failure to reach target yields by farmers was also found to influence the likelihood of being risk loving among the farmers. It was found that farmers with a high probability of not achieving target yields of 5.4 tonnes per hectare were less likely to be risk seeking. This could possibly mean that farmers who were not likely to obtain the target yield were not willing to take risks in their farming enterprise probably because of a lack of confidence due to frequent failure to reach target yields.

Table 7.0: Multinomial Logit Regression the determinants of farmers' risk status

\begin{tabular}{|c|c|c|c|c|c|c|}
\hline \multirow[b]{2}{*}{ Variable } & \multicolumn{3}{|c|}{ Risk Neutral } & \multicolumn{3}{|c|}{ Risk Loving } \\
\hline & Coefficient & Std. error & $\mathrm{P}>|\mathrm{z}|$ & Coefficient & Std. error & $\mathrm{P}>|\mathrm{z}|$ \\
\hline Age & -0.093 & 0.091 & 0.305 & -.084 & 0.143 & 0.555 \\
\hline Sex & $14.695^{* * *}$ & 0.812 & 0.000 & -1.168 & 0.950 & 0.219 \\
\hline Marital & -0.404 & 1.677 & 0.810 & $1.680 * *$ & 0.771 & 0.029 \\
\hline Edu & -1.041 & 0.771 & 0.177 & 0.223 & 0.270 & 0.409 \\
\hline Household Size & $0.413 * * *$ & 0.107 & 0.000 & -0.147 & 0.161 & 0.359 \\
\hline Riceexp & 0.049 & 0.095 & 0.609 & 0.123 & 0.144 & 0.394 \\
\hline Yield & -0.684 & 0.596 & 0.251 & 0.208 & 0.439 & 0.636 \\
\hline Landten & $8.286 * * *$ & 2.314 & 0.000 & $-1.426 * *$ & 0.757 & 0.060 \\
\hline Ofartio & 1.956 & 1.850 & 0.290 & $-0.432 * *$ & 0.195 & 0.027 \\
\hline Offincratio & $-26.368 * * *$ & 8.606 & 0.002 & 0.834 & 0.942 & 0.376 \\
\hline Extmeet & -0.066 & 0.243 & 0.786 & -0.077 & 0.207 & 0.709 \\
\hline Failprob & 0.071 & 0.081 & 0.384 & $-0.063 * *$ & 0.033 & 0.055 \\
\hline Constant & -22.274 & 6.728 & 0.001 & -0.952 & 3.291 & 0.772 \\
\hline BaseOutcome & Risk & Averse & Prob. $>\mathrm{Chi}^{2}$ & & & 0.0000 \\
\hline No. of Obs. & & 259 & PseudoR $^{2}$ & & & 0.410 \\
\hline Log Pseudo likeli & & -29.04 & WaldChi $^{2}(24)$ & & & 969.57 \\
\hline
\end{tabular}




\section{Conclusions and Policy Recommendations}

The study identified the frequency of risks that farmers have faced over the past five years prior to this survey and their perceived severities of damage when they occurred. It was realised that wind was the most frequent risk while pest and diseases followed. Wind was also perceived among the farmers to have had the highest average severity of damage during the periods in which they had occurred. Analysis of the risk attitudes of the farmers was done with the aid of Microsoft excel 2010 and STATA version 13 software. The data instrument was a risk attitudinal scale of 10 statements asking direct questions on farm decisions with a five-point Likert-response ranging from strongly agree as 1 through neutral as 3 to strongly disagree as 5 . The test of scale reliability using the Cronbach alpha coefficient rendered 4 statements with a high alpha coefficient. As such, the risk attitude was determined using those four statements. It was realised that $96.14 \%$ of the farmers were risk averse while $1.93 \%$ each of them were risk neutral and risk loving. The multinomial logit regression model was used to identify the factors affecting the risk nature of the respondents. The overall regression had a pseudo $\mathrm{R}^{2}$ coefficient of determination of $41.06 \%$. The results revealed varying determinants of the risk attitude of the respondents with different directions. It was identified that the sex of the farmer, household size, land tenure system and the ratio of non-farm income to rice farm income significantly affected the probability of risk neutrality whiles marital status, land tenure system and the probability of failure to achieve target yields were observed to significantly influence the probability of being risk-loving.

It is recommended that crops that can serve as wind breaks such plantain, banana, teak and eucalyptus should be cultivated in areas where rice farms exist. The insect control division of the Ministry of Food and Agriculture (Plant Protection Regulatory Services Directorate) should aid and monitor the rice farmers in their insect control regimes to minimize the effects of pests and disease on rice cultivation. Further study is recommended to identify the relationship between these risk attitudes and adoption of crop insurance. 


\section{References}

Adebusuyi B. S. (2004). "Stabilization of commodity market of interest to Africa. Paper presented at the workshop on Constraints to growth in Sub-Saharan Africa," Organized by the intergovernmental group of Twenty-Four in Pretoria-South Africa.

Adegeye, A. J. \& Dittoh, J. S. (1985) Essentials of Agricultural Economics (New Edition). Impact Publishers Nig. Ltd. Ibadan. Pp 106-126.

Akyoo, A. M., Temu A. E., \& Hella J. P. (2013). "Agricultural production risks, coping mechanism and potential for crop insurance in Tanzania," Time Journals of Agricultural and Veterinary Sciences, 1(1), 11-22.

Alderman, H. (2008). "Managing risk to increase efficiency and reduce poverty," Background paper for the World Development Report, World Bank.

Amanor-Boadu, V. (2012). "Rice Price Trends in Ghana (2006-20011) USAID/GHANA, Monitoring, Evaluation and Technical Support Services," USAID.

Bard S. K., \& Barry P. J. (2001). "Assessing Farmers' Attitudes toward Risk Using the "Closing-in" Method," Journal of Agricultural and Resource Economics, 26(1):248-260, Western Agricultural Economics Association.

Bernoulli, D. (1738). "Specimen Theorie Novae de Mensura Sortis," Comentrii Academiae Scientiarum Imperialis Petropolitanae, 5, 175-92 [Translated by Sommer, L. (1954). Econometrica, 22, 23-26. https://doi.org/10.2307/1909829

Crosetto P., \& Filippin A. (2013). "A Theoretical and Experimental Appraisal of Five Risk Elicitation Methods,” The German Socio- Economic Panel Study ISSN: 1864- 6689.

Deck, C., Lee, J., \& Reyes, J. (2010). "Personality and Consistency of risk taking behaviour: Experimental," Economic Science Institute, Chapman University.

DeVillis, R. F. (1991). "Scale Development: Theory and Applications," Applied Social Research Method Series, 26. Newbury Park: Sage.

Dohmen, T. Falk, A., HuÆman, D., \& Sunde, U. (n.d.) Individual Risk Attitudes: Measurement, Determinants and Behavioral Consequences Journal of the European Economic Association.

Ellis, F. (1998). "Household Strategies and Rural Livelihood Diversification," Journal of Development Studies, 35(1), 1-38. https://doi.org/10.1080/00220389808422553

Farsi, M. (2007). "Risk-Aversion and Willingness to Pay in Choice Experiments" D-MTEC, ETH Zurich, Switzerland CEPE Working Paper, 55.

Hao, A. (2010). "Uncertainty, Risk Aversion and Risk Management in Agriculture," Agriculture and Agricultural Science Procedia., (1), 152-156.

Harwood, J., Heifner, R., Coble, K., Perry, J., \& Somwaru, A. (1999). "Managing Risk in Farming: Concepts, Research, and Analysis," Market and Trade Economics Division and 
Resource Economics USDA Division, Economic Research Service, USDA Report No. 774.

Holt, C. A., \& Laury, S. K. (2002). "Risk Aversion and Incentives," American Economic Review, 92(5), 1644-1655 2002. https://doi.org/10.1257/000282802762024700

Hurley, T. M. (2010) A Review of Agricultural Production Risk in the Developing World. Working paper, Harvest choice

Kranjac-Berisavljevic', G., Blench, R. M. \& Chapman, R. (2003), Rice production and livelihoods in Ghana Multi-agency partnerships (maps) for Technical change in West African Agriculture

Maier J. \& Maximilian R. (2010). “A Note on Measuring Risk Aversion,” Preliminary Version Retrieved from www.edge-psge.net >jamb2010> papers.

Maré A. F. (2014). "Evaluating crop insurance as production risk management strategy," Unpublished Thesis-University of Free State.

Newbery, D.M.G \& Stiglitz J.E. (1981). The theory of commodity price stabilization: a study in the economics of risk. Oxford New York: Clarendon Press Oxford University Press. ISBN 9780198284178

Nmadu, J. N., Eze, G. P., \& Jirji, A. J. (2012). "Determinants of Risk Status of small scale farmers in Niger State, Nigeria," British Journal of Economics, Management and Trade, 2(2), 92-108. https://doi.org/10.9734/BJEMT/2012/1284

Nto P. O. O., Mbanasor J. A., Nto C. P. O., \& Osuala, A. E. (2013). "Evaluation of Risk Management Practices in Rice Production in Abia State, Nigeria," Swiss Journal of Management and Business Studies, 1(1).

Nunnally J. C. (1978) Psychometric theory. New York: McGraw Hill, 701

Reynaud A. \& Couture S. (2010). "Stability of Risk Preference Measures: Results from a Field Experiment on French Farmers," (UMT-EAU) French Agronomic Research Institute (INRA) (Arvalis Institut du Végétal and CETIOM). IMEBE conference at Bilbao

Sadati, S. A, Ghobadi, F. R., Sadati, S. A., Mohamadi, Y., Sharifi, O., \& Asakereh, A. (2010). "Survey of effective factors on adoption of crop insurance among farmers: A case study of Behbahan County," African Journal of Agricultural Research, 5(16), 2237-2242

\section{Copyright Disclaimer}

Copyright for this article is retained by the author(s), with first publication rights granted to the journal.

This is an open-access article distributed under the terms and conditions of the Creative Commons Attribution license (http://creativecommons.org/licenses/by/4.0/). 